\title{
Mechanisms of Proteinuria in Human Glomerulonephritis
}

\author{
Bryan D. Myers, Thomas B. Okarma, Stuart Friedman, Charles Bridges, \\ Jon Ross, Saied Asseff, and William M. Deen, Departments of Medicine \\ and Pathology, Stanford University Medical Center, Stanford, California \\ 94305; Department of Chemical Engineering, Massachusetts Institute of \\ Technology, Cambridge, Massachusetts 02142; The Geriatric Research \\ Education and Clinical Center, Palo Alto Veterans Administration Hospital, \\ Palo Alto, California 94304
}

A B S T R A C T We evaluated glomerular barrier function in 28 patients with glomerulonephritis. Neutral dextrans of graded size were used to characterize the size-selective properties of the barrier. Charge selectivity was characterized by electrofocusing excreted urinary proteins. A fractional IgG clearance (relative to freely permeable inulin), smaller or greater than $100 \times 10^{-5}$ was used to distinguish patients with minor (group I, $n=13$ ) and major (group II, $n=15$ ) urinary IgG leakage, respectively. Fractional clearances of smaller dextrans (radii 20-50 ) were similar, but those of larger dextrans (radii 52-60 $\AA$ ) were elevated in group II relative to group I patients. A model of solute transport through a bimodal pore size distribution revealed the values for pore radius in the lower mode to approximate 51-55 $\AA$ in both group I and group II patients. Pore radius in the upper mode, by contrast, was much larger in group II than in group I patients, approximating 87-97 vs. 72-77 $\AA$, respectively. Electrofocusing of urinary protein from group I patients revealed mostly albumin (isoelectric point 5.2). In group II patients, however, immunoglobulin excretion was copious. Moreover, the distribution of anionic, neutral, and cationic species (isoelectric points 5.5-8.5) in urinary and plasma eluates of $\operatorname{IgG}_{2}$ and $\operatorname{IgG}_{4}$ was similar. We conclude that when glomerulonephritis is associated with selective albuminuria, as in group $\mathrm{I}$, there is an isolated reduction of electrostatic retardation of relatively small anionic proteins. Major urinary IgG leakage (group II), however, appears to result from the development in the glomerular membrane of a subpopulation of enlarged pores that are highly permeable towards proteins of large size and varying charge.

Address reprint requests to Dr. Myers, Division of Nephrology, Stanford University Medical Center, Stanford, CA 94305.

Received for publication 30 November 1981 and in revised form 9 June 1982.

\section{INTRODUCTION}

Although proteinuria is an invariable finding in patients with proliferative glomerulonephritis, it may vary considerably in magnitude and composition. $\mathrm{Nu}$ merous attempts have been made to use differences in the urinary clearance of individual proteins of graded size to characterize the glomerular barrier to protein filtration (1-4). However, uncertainty regarding the fraction of filtered protein reabsorbed from proximal tubular fluid precludes an estimation of the Bowman's space-to-plasma concentration ratio of the test protein and hence a quantitative description of sieving characteristics of the glomerular barrier (5-7). Moreover, previous studies that have related the clearance of individual proteins to their molecular size have failed to consider the important influence of negatively charged components of the glomerular capillary wall on the rate of protein filtration (8-10).

These limitations of endogenous proteins as glomerular transport probes can be circumvented by the use of exogenous inert polymers, such as dextrans and polyvinylpyrrolidones (PVP) ${ }^{1}$, which are neither secreted nor reabsorbed by the tubule (11). By comparing the clearance of a dextran or PVP molecule of known size and charge density with that of freely permeable inulin, it is possible to accurately characterize the glomerulus as a macromolecular sieve $(12,13)$. Theoretical analyses of the permselective properties of the healthy human and rodent glomerulus toward neutral preparations of these polymers have indicated that mean pore radius approximates $50-55 \AA$ $(11,12,14)$. This also appears to hold true for the nephritic rodent glomerulus (15).

Of the large plasma proteins excreted in the urine of nephritic subjects, albumin and IgG are the most

\footnotetext{
${ }^{1}$ Abbreviations used in this paper: ERPF, effective renal plasma flow; GFR, glomerular filtration rate; PAH, paraaminohippurate; PVP, polyvinylpyrrolidone.
} 
copious. The former has an effective molecular radius of only $36 \AA$, but is highly anionic in physiological solution (isoelectric point $\sim 5.2$ ). Accordingly, enhanced transglomerular passage of albumin could, in theory, result exclusively from reduction of the density of fixed negative charges in the glomerular capillary wall $(9,10)$. Defective electrostatic barrier function is unlikely, however, to account for increased transglomerular passage of IgG. Two of the four major subclasses of IgG are only weakly charged and have isoelectric points close to neutrality (16). More importantly, determinations of the effective molecular dimensions of IgG reveal it to have a radius of $\sim 55 \AA(17,18)$, with the result that it should be excluded effectively from Bowman's space on the basis of its size alone.

In an effort to resolve the respective contributions to proteinuria of charge depletion and size defects in the glomerular filter, we have used a differential macromolecule clearance technique to study 28 patients with proliferative glomerulonephritis. Polydisperse neutral dextran (with effective molecular radii of 20 to $60 \AA$ ) was used to define the size-selective properties of the glomerular capillary wall. In the hope that the charge-selective properties of the glomerular filter in proliferative glomerulonephritis might be elucidated, we also subjected urinary and plasma eluates of IgG to electrofocusing. Our findings form the basis of this report.

\section{METHODS}

\section{Patient population}

Studies of glomerular barrier function were performed in 28 proteinuric patients with biopsy-proven glomerulonephritis. In each instance, the glomerulonephritis was characterized by increased glomerular cellularity, diffuse mesangial cell proliferation and intraglomerular immune complex deposition. Less uniform findings included extracapillary cell proliferation (seven cases), widening of the glomerular capillary wall (eight cases) and variable glomerulosclerosis. The use of the term "proliferative" to describe the glomerulonephritis encountered in this study is intended in a generic sense only and should not be taken to imply a homogeneous glomerular injury. Glomerulonephritis was associated with systemic lupus erythematosis in 16 patients. The nature of the immune complex disease in the remaining 12 patients was obscure.

The absence or presence of easily measurable quantities of IgG in the urine was used to divide patient studies into those associated with minor (group I) or major (group II) urinary IgG leakage. Urinary IgG concentration was $<20 \mu \mathrm{g} / \mathrm{ml}$ in the 13 patient studies comprising group I, and varied between 50 and $900 \mu \mathrm{g} / \mathrm{ml}$ in the remaining $15 \mathrm{pa}$ tient studies that comprised group II. The urinary excretion rate of a given protein represents the difference between its respective filtration and tubular reabsorption rates. Analyses of early proximal tubular fluid from proteinuric rats with experimental glomerular injuries suggest that increased rates of protein filtration overwhelm the tubular reabsorptive process and that most of the increased load of filtered protein is excreted (19-21). If this is also true of our nephritic population, then relative glomerular permeability to IgG will be reflected most faithfully by the clearance of IgG relative to that of freely permeable inulin $\left(\boldsymbol{\theta}_{\mathrm{lgg}}\right)$. It is important to note, therefore, that group I studies with minor urinary IgG leakage were associated uniformly with $\theta_{\operatorname{lgg}}<100 \times 10^{-5}$. Conversely, the corresponding values for $\theta_{\mathrm{lgG}}$ in group II studies with major IgG leakage were always $>100 \times 10^{-5}$.

Age was not significantly different between patients with minor and major urinary IgG leakage, ranging from 19 to 60 and 20 to $65 \mathrm{yr}$, respectively. The corresponding values for mean arterial pressure (diastolic pressure plus one-third of pulse pressure) were also similar, averaging $99 \pm 4$ and $105 \pm 3 \mathrm{mmHg}$, respectively (mean $\pm \mathrm{SEM}$ ). The study protocol was approved by the Stanford Committee for the Protection of Human Subjects in Research. Informed consent was obtained from each patient before the study began.

\section{Study protocol}

Each patient voided spontaneously after a diuresis had been established with oral water loading and in some cases with the oral administration of furosemide (80-120 mg). A priming dose followed by a constant infusion of inulin and para-aminohippurate (PAH) was administered to permit determination of the rates of glomerular filtration (GFR) and of effective renal plasma flow (ERPF), as described previously (22). $130 \mathrm{mg} / \mathrm{kg}$ Dextran-40 (Rheomacrodex, Pharmacia Fine Chemicals, AB, Uppsala, Sweden) was administered by slow $(\sim 10 \mathrm{~min})$ intravenous injection immediately after the inulin/PAH prime. At the end of a 40-60-min equilibration period, the bladder was emptied by voiding, after which three carefully timed 20-30-min urine collections were made. GFR and ERPF were expressed as the mean value of all three timed urine collections. From urine and plasma obtained during the first of these timed collections, fractional clearances (or sieving coefficients) of dextran-40 $\left(\theta_{D}\right)$ were computed with the equation

$$
\boldsymbol{\theta}_{\mathrm{D}}=\left[(\mathrm{U} / \mathrm{P})_{\mathrm{D}}\right] /\left[(\mathrm{U} / \mathrm{P})_{\text {in }}\right] \text {, }
$$

where $(U / P)_{D}$ and $(U / P)_{\text {in }}$ refer to the urine-to-midpoint plasma concentration ratios of dextran and inulin, respectively. The same urine and plasma samples were used for the determination of total protein concentration and the concentration and isoelectric points of albumin and IgG, respectively.

\section{Laboratory methods}

\section{EXOGENOUS CLEARANCE MARKERS}

For the GFR calculation, inulin concentration of urine and plasma was determined by the autoanalyzer method of Fjeldbo and Stamey (23). In this method, the fructose-specific reagent resorcinol, which is uninfluenced by the presence of dextran, was used. The autoanalyzer method of Harvey and Brothers (24) was used for the determination of PAH.

Separation of Dextran-40 and inulin in plasma and urine into narrow fractions $(\sim 2 \AA)$ was accomplished by gel permeation chromatography with columns packed with Sephacryl S-300 (Pharmacia Fine Chemicals). Three columns, 92-96 cm in length with internal diameters of $1.6 \mathrm{~cm}$ were used. Each column was calibrated with three narrow dextran 
fractions of known molecular size provided by the manufacturer (Pharmacia Fine Chemicals). With $0.3 \%$ buffered saline as eluent, $2.6 \mathrm{ml}$ eluted fractions were collected with an automatic fractionator (model S-80, Gilson Medical Electronics, Inc., Middleton, WI). The void volume $\left(\mathrm{V}_{0}\right)$ was determined with blue dextran, and the fractional volume available to the solute $\left(K_{\mathrm{av}}\right)$ was calculated as

$$
K_{\mathrm{av}}=\left(\mathrm{V}_{\mathrm{e}}-\mathrm{V}_{\mathrm{o}}\right) /\left(\mathrm{V}_{\mathrm{t}}-\mathrm{V}_{\mathrm{o}}\right),
$$

where $V_{e}$ is the elution volume of the solute and $V_{t}$ the total volume of the gel column (25). Effective molecular radii ( $r$ ) for individual dextran fractions were calculated from $K_{a v}$ (26). After gel permeation chromatography of plasma and urine, eluted fractions were assayed for dextran and inulin concentrations using a modification of the autoanalyzer anthrone method of Scott and Melvin (27). Although inulin and dextran are both anthrone positive, cross-reactivity was not encountered because of the differing elution volumes of each solute. Dextran standards were used for assaying the early dextran containing fractions $\left(\mathrm{K}_{\mathrm{av}}=0.5-0.2, \mathrm{r}=20-60 \AA\right)$. Separate inulin standards were used for assay of the smaller inulin molecules that were dispersed over an $r$-range of 11-18 $\AA\left(\mathrm{K}_{\mathrm{av}}=0.6-0.8\right)$. The average urine-to-plasma concentration ratio of the two peak inulin fractions was used for subsequent determination of fractional clearances. It should be noted that $(U / P)_{\text {in }}$ as determined by the anthrone method was not significantly different from that obtained by the resorcinol method.

\section{ENDOGENOUS PROTEIN PROBES}

The following techniques were used to characterize serum and urinary proteins:

Radial immunodiffusion. The concentration of albumin and IgG in plasma and urine was determined by radial immunodiffusion. To avoid the need for concentrating procedures, low level immunodiffusion plates (Kallestad Laboratories, Inc., Austin, TX) were used for the foregoing urinary protein determinations (28). These plates permit the measurement of albumin and IgG over a concentration range of 4-100 and $2-25 \mathrm{mg} / \mathrm{dl}$, respectively.

Electrofocusing. Analytical electrofocusing in thin-layer polyacrylamide gels was performed according to manufacturer's instructions (LKB Instruments, Inc., Rockville, MD, application note 250, December 1977). Gels were poured with $2 \%$ LKB ampholine, $\mathrm{pH}$ range $3.5-10$. Protein staining and gel preservation followed LKB application note RB423. Serum and urine were applied in $20-\mu$ l aliquots directly to the acrylamide slab gel with paper application strips. The acrylamide concentration was $5 \%$ with $3 \%$ cross-linkage, which resolves proteins of molecular weights $<200,000$ and excludes pentameric IgM from the gel matrix. To permit comparison between serum and urine, sera were diluted 1:10 with distilled water. Urine samples were then concentrated or diluted to achieve a ratio of urine-to-serum IgG of 0.5 for each patient.

Preparative flatbed electrofocusing of $5 \mathrm{ml}$ of whole patient serum using granulated gel was performed according to the LKB application note 198. After electrofocusing and determination of the $\mathrm{pH}$ gradient, the gel bed was separated into 30 fractions and electrofocused serum proteins were eluted with phosphate-buffered saline $(0.1 \mathrm{M}$ sodium phosphate, $0.15 \mathrm{M}$ sodium chloride, $\mathrm{pH}$ 7.2). Fractions were then dialyzed against distilled water using spectropore membranes with a molecular weight cutoff of $6,000-8,000$, whereafter each fraction was lyophilized for subsequent analysis of immunoglobulin content.

Immunoelectrophoresis. Rocket immunoelectrophoresis was performed according to Weeke (29). Glass slides were coated with agarose-containing goat anti-human IgG, antiIgM or anti-IgA at a concentration of $10 \mu \mathrm{l} / \mathrm{ml}$ of agarose. After congelation, one-fifth of the antiserum-containing agarose was removed along the narrow edge of the plate and replaced with an equal volume of agarose without antiserum. After congelation of the antiserum-free agarose, $2-\mathrm{mm}$ wells were punched in the gel and filled with $10 \mu \mathrm{l}$ of each serum fraction previously separated by preparative electrofocusing, and thereafter redissolved in phosphate-buffered saline. Electrophoresis was performed for $3 \mathrm{~h}$, with an LKB multiphore cooled to $10^{\circ} \mathrm{C}$ with $8 \mathrm{~V} / \mathrm{cm}$ applied to the gel. After electrophoresis, the slides were pressed, dried, stained, and destained, and the resulting rocket patterns photographed.

Crossed immunoelectrophoresis was performed utilizing fresh electrofocused acrylamide strips (30). Kodak glass slides (Eastman Kodak Co., Rochester, NY) were coated with $10 \mathrm{ml}$ of $1 \%$ agarose containing goat anti-human IgG, antiIgM, or anti-IgA serum at a concentration of $10 \mu \mathrm{l} / \mathrm{ml}$ of agarose. After congelation of the agarose, one-fifth of the antiserum containing agarose was removed along the wide edge of the plate and replaced with an equal volume of antiserum-free agarose. After congelation, the electrofocused strip was inverted and placed upon the antiserum-free agarose several millimeters from the boundary between antibody-containing and antibody-free agarose. The electrofocused protein bands were then electrophoresed into the antibody-containing agarose with a current of $8 \mathrm{~V} / \mathrm{cm}$ for $3 \mathrm{~h}$ at 8 and $12^{\circ} \mathrm{C}$. The resulting precipitant patterns were visualized by dehydration and staining according to the procedure of Weeke (29). To identify the electrofocused protein bands corresponding to the agarose immunoprecipitates, a stained electrofocused strip from a parallel run was superimposed upon the immunoprecipitate.

Immunoglobulin extraction from patient serum and urine. Immunoglobulins were extracted from serum and urine for analysis by electrofocusing using staphylococcal protein A Sepharose CL4B beads (Pharmacia Fine Chemicals). Before extraction, urine samples $(15-30 \mathrm{ml})$ were concentrated to $\sim 500 \mu \mathrm{l}$. Serum samples $(200-500 \mu \mathrm{l})$ were extracted without prior concentration. Samples of urine or serum were mixed in $500 \mu$ l of phosphate-buffered saline with 200-mg aliquots of staphylococcal protein A Sepharose CL4B beads previously swollen in phosphate-buffered saline. Samples were allowed to react overnight at room temperature on a rotating wheel. The beads were then transferred to polypropylene econo-columns (Bio-Rad Laboratories, Richmond, CA) and washed with $15 \mathrm{ml}$ of phosphate-buffered saline. Immunoglobulins were subsequently eluted with $15 \mathrm{ml}$ of glycine-HCl buffer $(0.1 \mathrm{M}, \mathrm{pH} 2.8)$. Glycine- $\mathrm{HCl}$ eluates were concentrated to $\sim 75 \mu \mathrm{l}$. $20-\mu \mathrm{l}$ aliquots were then applied to the electrofocusing gel for analysis. This technique resulted in the isolation of $\operatorname{IgG}_{1}, I G_{2}, I g G_{4}$, as well as trace quantities of $\operatorname{IgA}_{2}$ and $\operatorname{IgM}_{2}(31,32)$.

\section{Renal histopathology}

Renal tissue obtained by percutaneous biopsy from each patient was routinely prepared for and examined by light, electron, and immunofluorescence microscopy. For estimation of glomerular sialoglycoprotein content, sections were stained by the colloidal iron reaction (33). The intensity of staining was then graded as normal, reduced, or absent, in 
comparison with uninvolved portions of nephrectomy specimens that elsewhere contained renal cell carcinoma. Sclerotic glomeruli and sclerotic portions of glomeruli were avoided in making this assessment, but consolidated regions characterized by cellular proliferation were included. Electron micrographs of an average of three glomeruli were examined in each case and a qualitative estimate was made of the extent of foot process obliteration, ranging between 0 and $4+$. In these patients with active glomerulonephritis, foot process obliteration was difficult to assess in badly damaged and consolidated regions of glomeruli. Accordingly, nonconsolidated zones of the glomeruli were used preferentially for this assessment.

\section{Theoretical analysis of membrane pore structure}

The permselective properties of the glomerular capillary wall were evaluated using a heteroporous model of transmembrane solute transport. This model is a generalization of the isoporous model of Deen et al. (13) to the case of a membrane with two discrete pore radii, denoted by $r_{1}$ and $r_{2}$. The governing equations for the two-pore model, which in its present form applies only to uncharged solutes, are given in the Appendix. Using this idealization of the glomerular membrane, the Bowman's space-to-plasma concentration ratio $(\theta)$ of dextran molecules of known sizes can be used to derive values for the pore radii and for $\Omega$, the fraction of GFR permeating the larger pores of $r_{2}$. Because both dextran and inulin (the reference solute) are excreted by glomerular filtration and neither secreted nor reabsorbed by the renal tubule, $\boldsymbol{\theta}$ is equal to the fractional urinary dextran clearance. Accordingly, $\boldsymbol{\theta}$ for 15 partially permeant dextran fractions $(r=30-58 \AA)$ was used to estimate $r_{1}, r_{2}$, and $\Omega$ in each patient group.

\section{Statistical analysis}

All results are expressed as the mean \pm SEM. Student's $t$ test for unpaired data was used to evaluate the significance of intergroup differences observed.

\section{RESULTS}

Glomerular filtration and protein excretion. IgG was undetectable in the urine of three group I patients (Table I). In the remaining 10 group I patients the concentration of trace quantities of urinary IgG was uniformly $<20 \mu \mathrm{g} / \mathrm{ml}$. Because the immunodiffusion technique used in this study is insufficiently sensitive to determine IgG concentration $<20 \mu \mathrm{g} / \mathrm{ml}$, this latter value was used to estimate an upper bound for the fractional clearance of IgG in each patient. The maximum possible value observed for this index of urinary IgG leakage in group I patients was $89 \times 10^{-5}$. Fractional IgG clearances were uniformly in excess of this latter value $\left(109-9,367 \times 10^{-5}\right)$ in group II patients, in whom urinary IgG concentration was easily measurable $(50-900 \mu \mathrm{g} / \mathrm{ml})$. Thus, irrespective of whether urinary IgG concentration or fractional clearance of IgG was used as a criterion, patients with minor urinary IgG leakage (group I) were always clearly dis- tinguished from those with major urinary IgG leakage (group II).

The phenomenon of minor or major urinary IgG leakage also distinguished patients with respect to GFR. Thus, major relative to minor IgG leakage was associated with greater reduction of GFR, $20 \pm 4$ vs. $42 \pm 10 \mathrm{ml} / \mathrm{min}$ per $1.73 \mathrm{~m}^{2}$, respectively $(P<0.05)$. One group II patient with lupus nephritis (No. 24, Table I) had renal hyperemia. When this patient was excluded, mean ERPF in group II patients tended to be reduced relative to group I patients, $159 \pm 32$ vs. $264 \pm 51 \mathrm{ml} / \mathrm{min}$ per $1.73 \mathrm{~m}^{2}(P=\mathrm{NS})$. In keeping with the findings of others, depression of GFR was so disproportionate to the decline in ERPF that the filtration fraction rarely reached the normal value of 0.20 , averaging $0.15 \pm 0.01$ and $0.15 \pm 0.02$, in groups $I$ and $I I$, respectively (34).

The urinary excretion rate and fractional clearance of albumin tended to parallel that of IgG. Thus, minor urinary IgG leakage was associated with modest albuminuria $(476-2,737 \mu \mathrm{g} / \mathrm{min})$, whereas albumin excretion rate was heavy $(1,329-12,684 \mu \mathrm{g} / \mathrm{min})$ in patients with major urinary IgG leakage. Although there was some overlap, albumin excretion rate was significantly enhanced in group II relative to group I patients, $6,567 \pm 915$ vs. $1,242 \pm 232 \mu \mathrm{g} / \mathrm{min}$, respectively $(P<0.001)$. A similar disparity was observed for fractional albumin clearance, the respective values in group II vs. group I patients averaging $2,205 \pm 603$ vs. $179 \pm 45 \times 10^{-5}(P<0.005)$. Given the difference in the magnitude of proteinuria, it is not surprising that group II patients were more hypoproteinemic than group I patients, $4.8 \pm 0.3$ vs. $5.9 \pm 0.3 \mathrm{~g} / \mathrm{dl}$, respectively $(P<0.01)$. The respective values for serum albumin were $2,129 \pm 235$ and $3,162 \pm 270 \mathrm{mg} / \mathrm{dl}$ $(P<0.01)$, whereas corresponding values for serum IgG were $494 \pm 100$ and $809 \pm 101 \mathrm{mg} / \mathrm{dl}$, respectively $(P<0.05)$.

Urinary protein composition. Sera and urine samples from six group I and 10 group II patients were analyzed by analytical electrofocusing. Fig. 1 depicts results representative of each patient group. Fig. la illustrates a group I patient whose serum proteins (S) displayed marked microheterogeneity spanning a $\mathbf{p H}$ range of 4-10 with predominant albumin and prealbumin species at $\mathrm{pH}$ 5.2. The corresponding urine sample $(\mathrm{U})$ revealed restricted heterogeneity displaying only the albumin species of pH 5.2. All six group I patients exhibited this pattern with urinary excretion of anionic proteins restricted to isoelectric points $<6.0$. Fig. lb depicts the electrofocusing pattern of a representative patient from group II. Once again serum protein microheterogeneity was evident with isoelectric points ranging from 4 to 10 . In contrast to group 
I patients, however, the electrofocusing pattern of excreted urinary proteins matched that of serum and also spanned a pH range of 4-10. All group II patients exhibited a pattern of heterogeneous urinary protein excretion.

The foregoing patients were studied further by isolating immunoglobulins from sera and urine with staph protein A-Sepharose beads and subjecting the eluate to analytical electrofocusing. These results are shown in Fig. 2. Fig. 2a depicts the electrofocusing pattern of the staph protein $A$ eluate from the serum $(S)$ and urine (U) of a group I patient. $\operatorname{IgA}_{2}, \operatorname{IgG}_{1}, \operatorname{IgG}_{2}$, and $\operatorname{IgG}_{4}$ species were present in the serum eluate and electrofocused between $\mathrm{pH} 5.5$ and $10\left(\mathrm{IgM}_{2}\right.$ was excluded by the acrylamide gel and appeared as a precipitate at the application point marked by the arrow).

TABLE I

Renal Function and Protein Clearances

\begin{tabular}{|c|c|c|c|c|c|c|c|c|c|c|}
\hline & & $\theta_{\operatorname{lgc}}$ & $\theta_{\text {alb }}$ & GFR & ERPF & $\mathrm{FF}^{\bullet}$ & $U_{\text {alb }}$ & $U V_{\mathrm{I}_{\mathrm{GC}} \mathrm{Cl}}$ & Palb $\$$ & $P_{I_{g} G} \$$ \\
\hline & & \multicolumn{2}{|c|}{$\times 10^{-s}$} & \multicolumn{3}{|c|}{$\mathrm{ml} \cdot \mathrm{min}^{-1} \cdot\left(1.73 \mathrm{~m}^{2}\right)^{-1}$} & \multicolumn{2}{|c|}{$\mu g / \min$} & \multicolumn{2}{|c|}{$m g / d l$} \\
\hline \multicolumn{11}{|l|}{ Group I } \\
\hline \multirow[t]{13}{*}{ Patient No. } & 1 & 0 & 562 & 5 & 95 & 0.06 & 572 & 0 & 2,490 & 800 \\
\hline & 2 & 0 & 18 & 67 & 329 & 0.21 & 476 & 0 & 3,860 & 1,278 \\
\hline & 3 & 0 & 68 & 84 & 444 & 0.19 & 1,838 & 0 & 2,780 & 715 \\
\hline & 4 & $<12$ & 16 & 121 & 652 & 0.18 & 521 & $<114$ & 3,530 & 1,076 \\
\hline & 5 & $<28$ & 130 & 66 & 425 & 0.16 & 2,737 & $<193$ & 3,236 & 1,058 \\
\hline & 6 & $<32$ & 246 & 17 & 111 & 0.16 & 747 & $<17$ & 1,720 & 552 \\
\hline & 7 & $<47$ & 187 & 12 & 91 & 0.13 & 1,030 & $<76$ & 4,310 & 1,130 \\
\hline & 8 & $<53$ & 135 & 14 & 105 & 0.13 & 1,020 & $<63$ & 4,540 & 1,007 \\
\hline & 9 & $<53$ & 186 & 25 & 420 & 0.06 & 780 & $<40$ & 1,560 & 283 \\
\hline & 10 & $<61$ & 108 & 25 & 120 & 0.21 & 769 & $<164$ & 2,730 & 1,290 \\
\hline & 11 & $<81$ & 442 & 12 & 103 & 0.12 & 1,686 & $<34$ & 2,860 & 318 \\
\hline & 12 & $<89$ & 54 & 32 & 174 & 0.18 & 945 & $<33$ & 4,590 & 717 \\
\hline & 13 & $<89$ & 180 & 60 & 366 & 0.17 & 3,019 & $<148$ & 2,900 & 287 \\
\hline Mean & & & 179 & 42 & 264 & 0.15 & 1,242 & & 3,162 & 809 \\
\hline$\pm \mathrm{SEM}$ & & & 45 & 10 & 51 & 0.01 & 232 & & 270 & 101 \\
\hline \multicolumn{11}{|l|}{ Group II } \\
\hline \multirow[t]{15}{*}{ Paitent No. } & 14 & 109 & 474 & 13 & 87 & 0.15 & 1,709 & 147 & 2,600 & 1,130 \\
\hline & 15 & 155 & 376 & 30 & 203 & 0.15 & 3,805 & 470 & 3,320 & 99 \\
\hline & 16 & 183 & 658 & 54 & 495 & 0.11 & 10,678 & 1,033 & 2,100 & 729 \\
\hline & 17 & 207 & 868 & 14 & 71 & 0.20 & 2,509 & 120 & 1,920 & 385 \\
\hline & 18 & 262 & 762 & 19 & 144 & 0.13 & 6,305 & 587 & 4,160 & 1,126 \\
\hline & 19 & 262 & 559 & 57 & 211 & 0.29 & 5,617 & 182 & 1,620 & 112 \\
\hline & 20 & 311 & 1,619 & 14 & 82 & 0.18 & 4,988 & 225 & 2,300 & 540 \\
\hline & 21 & 323 & 1,157 & 6 & 57 & 0.11 & 1,327 & 161 & 2,750 & 1,192 \\
\hline & 22 & 488 & 1,310 & 37 & 247 & 0.15 & 10,140 & 626 & 1,750 & 290 \\
\hline & 23 & 645 & 2,543 & 22 & 64 & 0.34 & 11,267 & 770 & 1,970 & 531 \\
\hline & 24 & 1,800 & 3,975 & 28 & 1,260 & 0.02 & 8,280 & 1,068 & 530 & 151 \\
\hline & 25 & 1,677 & 1,694 & 25 & 170 & 0.15 & 7,515 & 1,955 & 1,620 & 425 \\
\hline & 26 & 2,555 & 2,738 & 6 & 112 & 0.05 & 4,586 & 374 & 2,730 & 239 \\
\hline & 27 & 3,456 & 5,455 & 5 & 54 & 0.09 & 7,100 & 1,087 & 1,670 & 103 \\
\hline & 28 & 9,367 & 8,880 & 15 & 235 & 0.06 & 12,684 & 847 & 881 & 56 \\
\hline Mean & & 1,453 & 2,205 & 20 & 232 & 0.15 & 6567 & 643 & 2128 & 494 \\
\hline$\pm \mathrm{SEM}$ & & 624 & 603 & 4 & $7 \dot{9}$ & 0.02 & 915 & 130 & 235 & 100 \\
\hline$P(\mathbf{I}$ vs. II $)$ & & - & $<0.005$ & $<0.05$ & NS & NS & $<0.001$ & - & $<0.01$ & $<0.05$ \\
\hline
\end{tabular}

- FF, filtration fraction.

I UV, urine excretion rate.

$\S \mathrm{P}$, plasma concentration. 


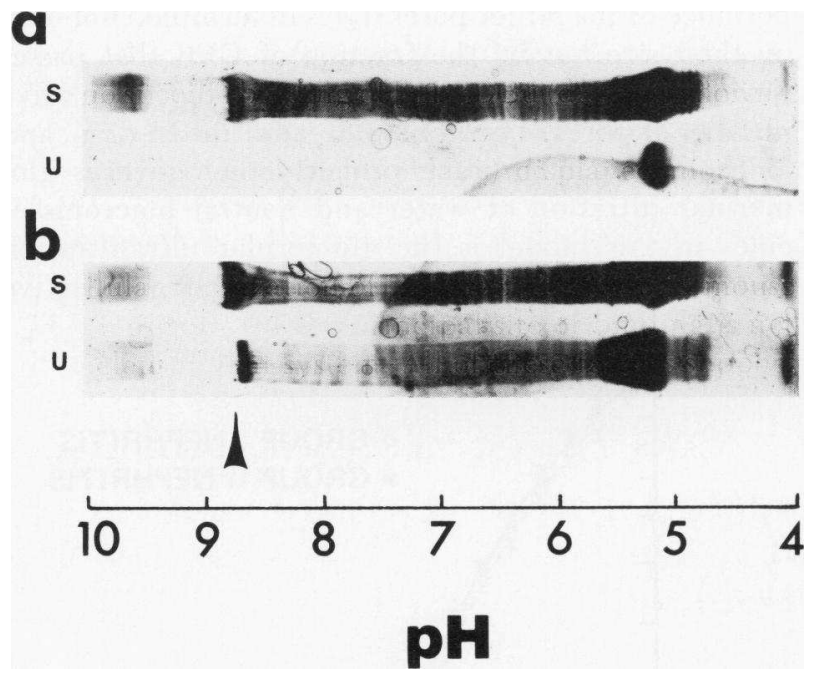

Figure 1 Electrofocusing profile of serum and urinary protein. Pattern a (upper panel) is from a representative group I patient (No. 1, Table I). Serum (S) is heterogeneous, containing proteins with isoelectric points ranging from 4 to 10 . By contrast, urine (U) contains only a broad albumin peak at $\mathrm{a} \mathrm{pH}$ of 5.2. Pattern $\mathrm{b}$ (lower panel) is from a representative group II patient (No. 27, Table I). Urinary protein $(\mathrm{U})$ is similarly heterogeneous to that of serum (S) and spans the full $\mathrm{pH}$ range of the gel.

The urine was negative for immunoglobulin. Similar analysis of the remaining group I patients gave identical results.

Analysis of the immunoglobulins eluting from staphylococcal protein A of serum and urine of group II patients revealed two distinct patterns. Fig. $2 \mathrm{~b}$ depicts a representative pattern obtained in five group II patients with moderate urinary $\operatorname{IgG}$ leakage $\left(\boldsymbol{\Theta}_{\mathrm{lgG}}=109\right.$ $\left.323 \times 10^{-5}\right)$. As in group $I$, serum eluate electrofocused between $\mathrm{pH} 5.5$ and 10.0. However, the immunoglobulin eluate from urine showed restriction of heterogeneity with an absence of cationic immunoglobulin species with an isoelectric point above 8.6. Fig. 2c depicts an immunoglobulin electrofocusing pattern from serum and urine representative of all but one of five group II patients with massive urinary IgG leakage $\left(\Theta_{\mathrm{IgG}}=488-3,458 \times 10^{-5}\right)$. In four members of this subgroup, the distribution of electrofocused urinary immunoglobulin exactly paralleled that obtained from serum. The single exception was patient 23 (Table I), who showed an electrofocusing pattern indistinguishable from that in Fig. $2 b$ (urinary cationic restriction). This correlation suggests that the appearance of cationic IgG in urine may be a function of the magnitude of the filtered IgG load.

The distribution of immunoglobulin molecules in the serum of selected group II patients was determined

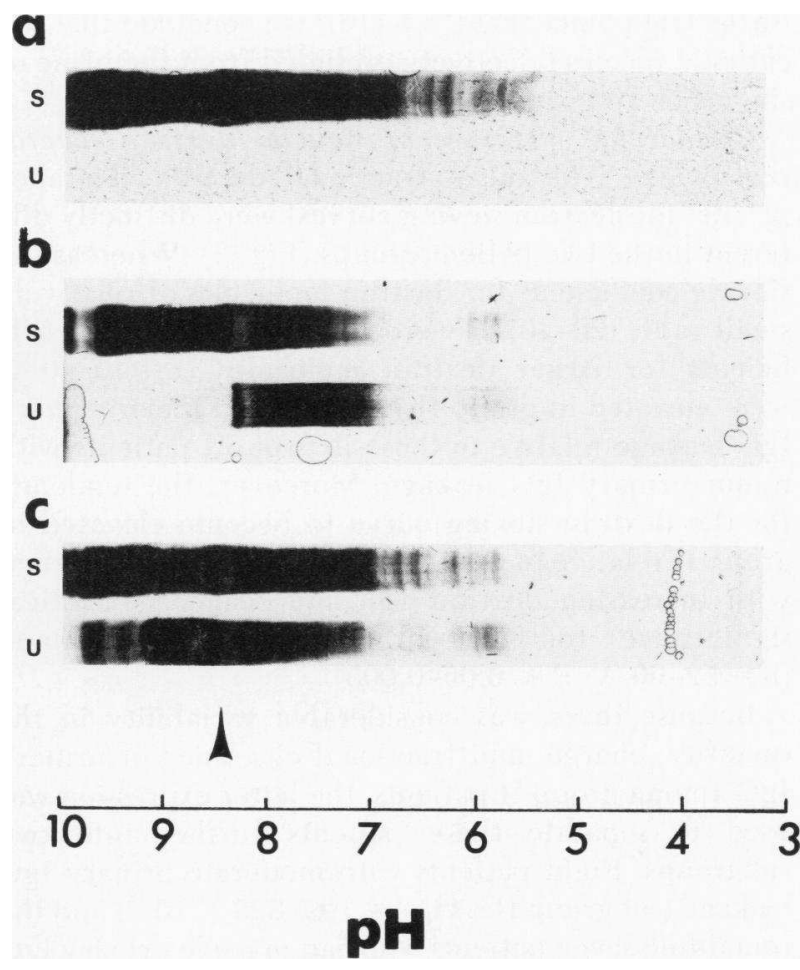

Figure 2 Analytical electrofocusing profile of immunoglobulin eluate of serum $(\mathrm{S})$ and urine $(\mathrm{U})$. Eluted serum immunoglobulins ( $\operatorname{IgG}_{1}, \operatorname{IgG}_{2}, \operatorname{IgG}_{4}$ and $\operatorname{IgA} A_{2}$ ) electrofocused between 5.5 and 10. Pentameric $\operatorname{IgM}_{2}$ is excluded from the gel and appears as a precipitate indicated by the arrow. Pattern (a) (upper panel) is from a group I patient (No. 4, Table I) and reveals urinary immunoglobulin to be undetectable. Pattern (b) (middle panel) is from a group II patient (No. 17, Table I). Urinary immunoglobulins are restricted relative to those in serum and span a $\mathrm{pH}$ range from 5.5 to 8.5. This pattern was found in 6 of 10 group II patients. Pattern (c) (bottom panel) is also from a group II patient (No. 25, Table I). Urinary immunoglobulin now has an identical banding pattern to that in serum with species present from $\mathrm{pH} 5.5$ to 10.0 . This pattern was found in each of the remaining group II patients thus studied.

by preparative electrofocusing and rocket immunoelectrophoresis. Such analysis revealed IgG to be present in fractions between $\mathrm{pH} 4.5$ and $10 ; \operatorname{IgA}$ between 3.5 and 7.5, and IgM between 3.5 and 7.0. Thus, only IgG species displayed isoelectric points above $\mathrm{pH} 7.5$. The identity of the cationic immunoglobulins present in the serum of group II study patients was confirmed by crossed immunoelectrophoresis. Cationic immunoglobulin species eluted from the staphylococcal protein A beads from both serum and urine of group II patients formed an immunoprecipitate with anti-human IgG but not with anti-human IgA or IgM. Because staphylococcal protein $A$ binds only $\operatorname{IgG}_{1}, \operatorname{IgG}_{2}$, and $\operatorname{IgG}_{4}$, and of these, only $\operatorname{IgG}_{1}$ has been shown to exhibit 
isoelectric points above 8.5 (16), we conclude that the cationic species selectively excluded from the urine of six out of 10 group II patients was IgG $_{1}$.

Glomerular filtration of neutral dextran macromolecules. The mean fractional dextran clearance profiles (or dextran sieving curves) were distinctly different in the two patient groups (Fig. 3). Whereas the sieving coefficients for dextran molecules of relatively small radii $(20-40 \AA)$ were similar, the sieving coefficients for larger dextran molecules $(r=40-60 \AA)$ were elevated in group II patients with major urinary IgG leakage relative to those in group I patients with minor urinary IgG leakage. Moreover, the tendency for the dextran sieving curve to become elevated in group II relative to group I patients became magnified with increasing dextran size and reached statistical significance for the largest fractions examined ( $\mathrm{r}=52-60 \AA, P<0.05-0.005)$.

Because there was considerable variability in the quantity, charge, and fractional clearance of urinary IgG among group II patients, the latter expression was used to separate these patients further into two subgroups. Eight patients with moderate urinary IgG leakage (subgroup IIa, $\theta_{\mathrm{IgG}}=109-323 \times 10^{-5}$ ) and the remaining seven patients who had massive urinary IgG leakage (subgroup IIb, $\theta_{\mathrm{IgG}}=488-9,367 \times 10^{-5}$ ) had similar rates of glomerular filtration $(26 \pm 7$ and $23 \pm 4$ $\mathrm{ml} / \mathrm{min}$ per $\left.1.73 \mathrm{~m}^{2}\right)$ and renal plasma flow $(169 \pm 51$ and $150 \pm 42 \mathrm{ml} / \mathrm{min}$ per $1.73 \mathrm{~m}^{2}$ ). However, plasma protein concentration was higher in the former than the latter subgroup, $5.5 \pm 0.4$ vs. $4.1 \pm 0.3 \mathrm{~g} / \mathrm{dl}$, respectively $(P<0.01)$. The fractional dextran clearance profiles also differed between these subgroups (Fig. 4). In subgroup IIb relative to subgroup IIa, the sieving coefficients for dextran molecules of relatively small radius were depressed. The opposite was true of sieving coefficients for dextrans of large radius which were strikingly elevated. Some of these differences were statistically significant at the small and large radius end of the sieving curves (Fig. 4). Comparison of the data in Tables II and III reveals that the sieving curve in subgroup IIa tended to be uniformly elevated above that in group I over the entire range of molecular sizes examined. Although this difference failed to reach statistical significance, these findings suggest that a selective and graded elevation of the large radius portion of the sieving curve $(r=40-60 \AA)$ accompanies progression from minor through moderate to massive urinary IgG leakage.

Analysis of glomerular pore-size distribution. The differences in dextran fractional clearances among the groups of patients studied was interpreted in terms of a model (described in the Appendix) in which the glomerular capillary wall is assumed to possess two discrete pore sizes, with radii $r_{1}$ and $r_{2}$. The relative im- portance of the larger pores $\left(r_{2}\right)$ is determined not only by their size but by the fraction of GFR that passes through them $(\Omega)$, which depends also on the relative number of pores of each type. In addition to $r_{1}, r_{2}$, and $\Omega$, the fourth membrane property that governs glomerular filtration of water and neutral macromolecules in this model is the glomerular ultrafiltration coefficient, $K_{f}$, defined here as the product of effective

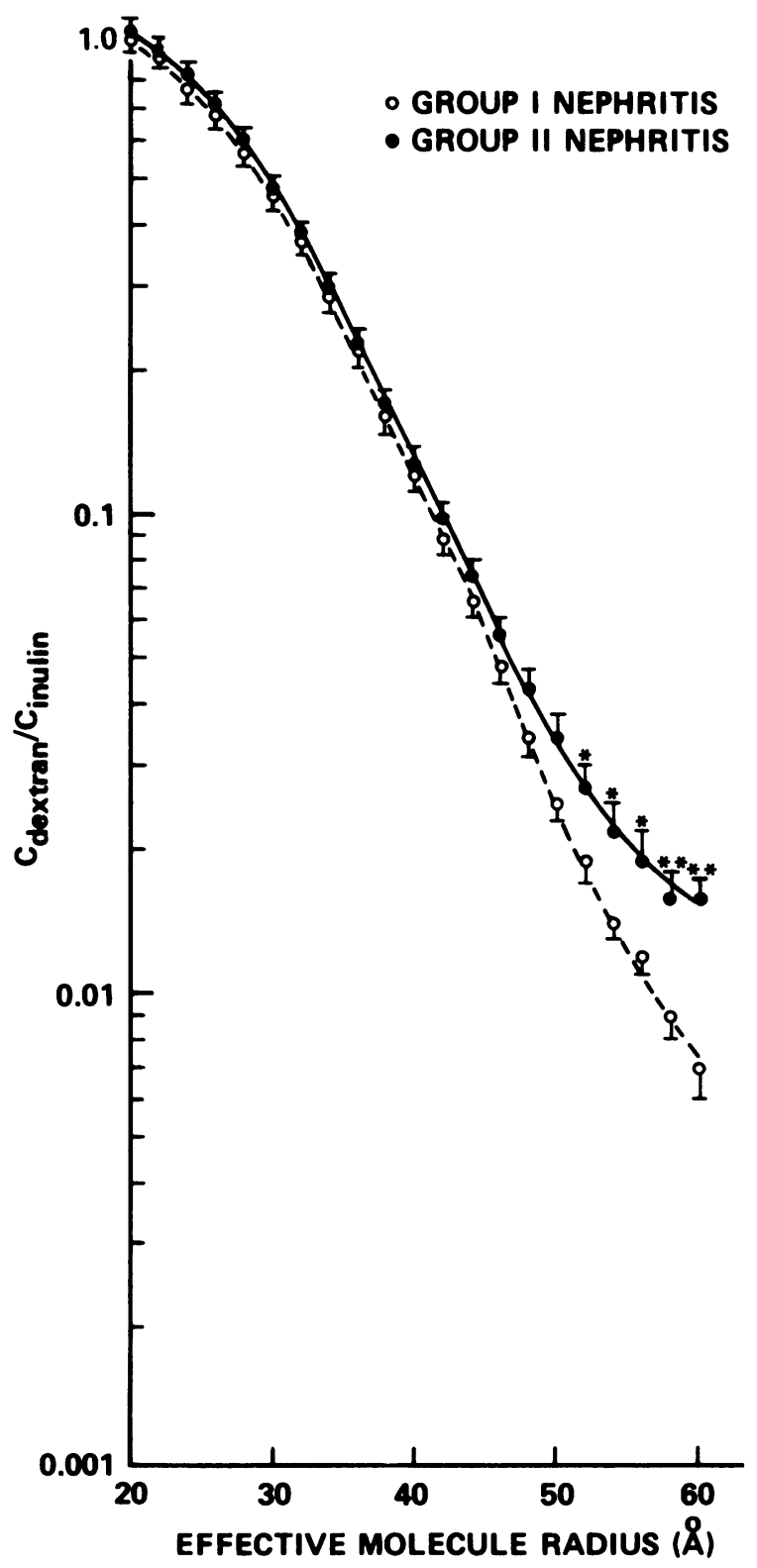

Figure 3 Fractional dextran clearance profile (or dextran sieving curve) for the glomerulus in nephritic subjects with minor urinary IgG leakage (group I, O) or major urinary IgG leakage (group II, O). Results are expressed as

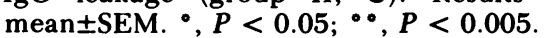




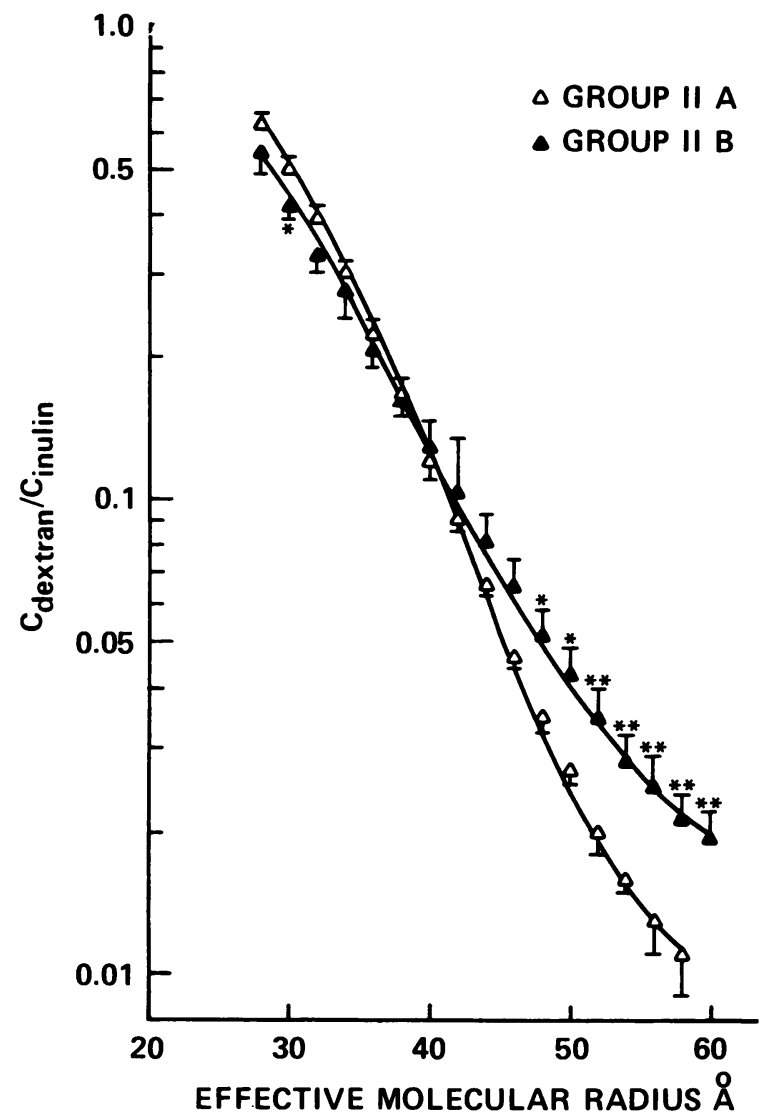

Figure 4 Fractional dextran clearance profiles in two subgroups of patients with major urinary IgG leakage (group II). Subgroup IIa $(\Delta)$ comprises eight patients in whom $\theta_{\operatorname{lgG}} \leq 400 \times 10^{-5}$. Subgroup IIb $(\Delta)$ comprises the remaining seven patients in whom $\theta_{\mathrm{IgC}} \geq 400 \times 10^{-5}$. ${ }^{\circ}$, $P<0.05 ; \stackrel{\circ}{\circ} P<0.02$.

hydraulic permeability and total glomerular capillary surface area in the two kidneys. $K_{\mathrm{f}}$ was calculated independently of dextran sieving coefficients, based on values of ERPF, filtration fraction, transcapillary hydraulic pressure difference $(\Delta P)$, and afferent arteriolar (systemic) protein concentration (34). The one needed input that could not be measured in this study was $\Delta \mathbf{P}$, so that all calculations were performed using a range of values $(30-50 \mathrm{~mm} \mathrm{Hg})$ that should bracket the actual transcapillary hydraulic pressure difference.

Calculated membrane parameters for groups I, II, IIa, and IIb are shown in Table IV. On the assumption that $\Delta \mathbf{P}$ was similar in patients with varying degrees of urinary IgG excretion, $K_{f}$ in group II was one-third to one-half that in group $I$, depending on the value of $\Delta \mathrm{P}$ chosen. The calculated radius of the smaller pores $\left(r_{1}\right)$ was quite similar in all groups and for all choices of $\Delta \mathrm{P}$, falling in the range of 51-55 $\AA$. There were, however, pronounced differences between groups I and II in the size and degree of participation of the larger pores. This second pore population had a larger radius $\left(r_{2}\right)$ in group II than in group $I, 87-97$ vs. 72$77 \AA$. Despite the lower fraction of GFR passing through the second pore population in group II than in group I (0.07-0.10 vs. 0.11-0.17), the larger size of these pores was sufficient to account for the higher fractional clearances seen in group II for the largest dextrans (Table II, Fig. 3). On the basis of previously reported data in healthy volunteers $(28,35)$ we used the present two-pore model to calculate pore characteristics for the normal human glomerulus. These calculations revealed that $r_{1}=50.0 \AA, r_{2}=67.4 \AA$, and $\Omega=0.299$ for $\Delta P=40 \mathrm{~mm} \mathrm{Hg}$. Thus, values of $r_{1}$ and $r_{2}$ in group I nephritics were only slightly higher than in healthy controls, while the corresponding value of $\Omega$ was lower.

The quantity $\Omega^{\prime}$ in Table IV is the fraction of total pore cross-sectional area contributed by the larger pore size, 0.02-0.04 and 0.06-0.09 in groups II and I, respectively. Thus, at most $9 \%$ of the pore area is inferred to be occupied by the larger pores. Values of $\Omega^{\prime}$ are smaller than the corresponding values of $\Omega$ because the

TABLE II

Fractional Dextran Clearance Profiles

\begin{tabular}{lccccccccccc}
\hline & \multicolumn{10}{c}{$\theta_{\mathrm{D}}$} \\
\cline { 2 - 11 } & 20 & 24 & 28 & 32 & 36 & 40 & 44 & 48 & 52 & 56 & 60 \\
\hline & & & & & & $A$ & & & & & \\
Group I $(n=13)$ & & & & & & & & & & & \\
$\quad$ Mean & 0.955 & 0.746 & 0.558 & 0.368 & 0.218 & 0.119 & 0.065 & 0.034 & 0.019 & 0.012 & 0.007 \\
$\quad$ SEM & 0.032 & 0.031 & 0.030 & 0.027 & 0.017 & 0.009 & 0.005 & 0.003 & 0.002 & 0.001 & 0.001 \\
Group II $(n=15)$ & & & & & & & & & & & \\
$\quad$ Mean & 0.978 & 0.817 & 0.594 & 0.369 & 0.223 & 0.126 & 0.074 & 0.043 & 0.027 & 0.019 & 0.016 \\
$\quad$ SEM & 0.065 & 0.032 & 0.031 & 0.018 & 0.012 & 0.007 & 0.005 & 0.004 & 0.003 & 0.003 & 0.002 \\
$P$ (I vs. II) & NS & NS & NS & NS & NS & NS & NS & NS & $<0.05$ & $<0.05$ & $<0.005$ \\
\hline
\end{tabular}


TABLE III

Fractional Dextran Clearance Profiles in Subgroups with Major Urinary IgG Leakage

\begin{tabular}{|c|c|c|c|c|c|c|c|c|c|c|c|}
\hline & \multicolumn{11}{|c|}{$\theta_{\mathrm{D}}$} \\
\hline & 20 & 24 & 28 & 32 & 36 & 40 & 44 & 48 & 52 & 56 & 60 \\
\hline & & & & & & $\dot{A}$ & & & & & \\
\hline \multicolumn{12}{|c|}{ Group IIa $(n=8)$} \\
\hline Mean & 1.032 & 0.864 & 0.630 & 0.400 & 0.230 & 0.123 & 0.066 & 0.035 & 0.020 & 0.013 & 0.009 \\
\hline \pm SEM & 0.088 & 0.032 & 0.030 & 0.018 & 0.010 & 0.005 & 0.003 & 0.002 & 0.002 & 0.002 & 0.0003 \\
\hline \multicolumn{12}{|c|}{ Group IIb $(n=7)$} \\
\hline Mean & 0.898 & 0.756 & 0.547 & 0.333 & 0.214 & 0.130 & 0.082 & 0.052 & 0.035 & 0.025 & 0.019 \\
\hline \pm SEM & 0.095 & 0.055 & 0.060 & 0.027 & 0.024 & 0.015 & 0.010 & 0.007 & 0.005 & 0.004 & 0.003 \\
\hline$P$ (Ila vs. IIb) & NS & NS & NS & NS & NS & NS & NS & $<0.05$ & $<0.02$ & $<0.02$ & $<0.02$ \\
\hline
\end{tabular}

larger the pores the less flow resistance there is per unit of cross-sectional area. Since the pressure drop across all of the parallel pores is the same, a greater flow rate per unit area is obtained in the larger pores.

The results in Table IV in subgroups IIa and IIb indicate that in this case the observed differences in fractional dextran clearance profiles (Table III, Fig. 4) may more readily be attributed to different relative numbers of large and small pores rather than to differences in pore radius. Similar values of $r_{2}$ were obtained for subgroups IIa and IIb, 82-95 $\AA$ and 83$89 \AA$, respectively (depending on the assumed $\Delta \mathrm{P}$ ).
$\Omega$ in subgroup IIb, however, was roughly twice that in subgroup IIa, which indicates that in subgroup IIb a much larger fraction of glomerular filtrate permeated the larger pores. This greater participation of the larger pores in water filtration is calculated to be the result of a two- to threefold higher fraction of pore area $\left(\Omega^{\prime}\right)$ that they occupy in subgroup IIb than in subgroup IIa. Whereas the enhanced fractional clearances of large dextrans in group II relative to group I were explained by larger values of the upper pore radius, the enhanced filtration of large dextrans in subgroup IIb relative to subgroup IIa was attributable

TABLE IV

Calculated Glomerular Membrane Parameters ${ }^{\circ}$

\begin{tabular}{|c|c|c|c|c|c|}
\hline$\Delta \mathrm{P}$ & Parameter & Group I & Group II & Subgroup IIa & Subgroup IIb \\
\hline \multicolumn{6}{|c|}{$\mathrm{mm} \mathrm{Hg}$} \\
\hline \multirow[t]{5}{*}{30} & $K_{\mathrm{f}}$ & 6.1 & 2.0 & 2.6 & 1.3 \\
\hline & $r_{1}$ & 50.9 & $53.7 \rrbracket$ & $53.5 !$ & 52.6 \\
\hline & $r_{2}$ & 72.4 & 86.9 & 81.7 & $83.2 \downarrow$ \\
\hline & $\Omega$ & 0.169 & 0.099 & 0.091 & 0.158 \\
\hline & $\mathbf{\Omega}^{\prime}$ & 0.091 & 0.040 & 0.041 & 0.070 \\
\hline \multirow[t]{5}{*}{40} & $K_{f}$ & 2.5 & 1.1 & 1.3 & 0.8 \\
\hline & $r_{1}$ & 53.7 & 54.7 & 54.8 & 53.7 \\
\hline & $r_{2}$ & 76.8 & 93.7 & 90.2 & 87.4 \\
\hline & $\Omega$ & 0.110 & 0.074 & 0.059 & 0.128 \\
\hline & $\mathbf{\Omega}^{\prime}$ & 0.057 & 0.027 & 0.025 & 0.053 \\
\hline \multirow[t]{5}{*}{50} & $K_{f}$ & 1.7 & 0.8 & 0.9 & 0.6 \\
\hline & $\mathbf{r}_{1}$ & 53.8 & 54.9 & 55.0 & 53.9 \\
\hline & $r_{2}$ & 77.1 & $97.2 \downarrow$ & 95.0 & 88.6 \\
\hline & $\Omega$ & 0.107 & 0.066 & 0.049 & 0.121 \\
\hline & $\mathbf{\Omega}^{\prime}$ & 0.055 & 0.022 & 0.017 & 0.048 \\
\hline
\end{tabular}

- Units are $\left(\mathrm{ml} \cdot \mathrm{min}^{-1} \cdot \mathrm{mm} \mathrm{Hg}^{-1} \cdot\left(1.73 \mathrm{~m}^{2}\right)^{-1}\right.$ for $K_{\mathrm{f}}$ (two kidneys), and angstroms for $\mathrm{r}_{1}$ and $r_{2}\left(\Omega\right.$ and $\Omega^{\prime}$ are dimensionless). Symbols are as defined in text.

I Estimated $95 \%$ confidence limit does not overlap with that for group I (determined for $r_{1}$, $r_{2}$, and $\Omega$ only). 
to a greater fraction of pore area occupied by the larger radius pores.

Glomerular morphology. No attempt was made to relate glomerular morphology to membrane function in five patients (two in group I and three in group II), in whom the interval between the biopsy and clearance study exceeded $4 \mathrm{wk}$. In the remaining 23 patients, electron microscopy uniformly revealed variable replacement of discrete and interdigitating foot processes by a continuous layer of epithelial cytoplasm. This finding, which is taken to reflect depletion of glomerular polyanion (36) varied among patients so that loss of foot processes ranged from $\sim 25(1+)$ to $100 \%(4+)$ of capillary wall surface area examined.

Tissue was available for colloidal iron staining in 16 patients (eight from each group) in whom the biopsy was contemporaneous with the clearance study. The intensity of staining was normal in a single instance in each patient group. In the remaining patients the Prussian blue stain was clearly reduced in intensity but never entirely absent. In keeping with the heterogeneous nature of the underlying glomerulonephritis, reduced colloidal iron uptake was in some patients of each group confined to segments of some but not all glomeruli. In others, glomerular uptake of colloidal iron was reduced in a diffuse and global fashion. Foot process fusion tended to be more extensive in group II relative to group I patients. There was, however, no discernible difference in the reduction of colloidal iron uptake between the two patient groups.

\section{DISCUSSION}

With the use of dextran polymers of broad size distribution and varying charge density, it has been shown that rodent nephrotoxic serum nephritis is accompanied by reduction of fixed negative charges on the diseased glomerular capillary wall leading to less restriction of circulating polyanions $(10,13,37)$. Our analysis of excreted urinary proteins provides indirect evidence that this is also true of patients with proliferative glomerulonephritis. Among group I patients, urinary protein was almost exclusively composed of anionic albumin (Fig. 1). Among group II patients, by contrast, excreted urinary protein was heterogeneous in composition. As judged by electrofocusing of urinary IgG eluate, however, the IgG permeable region of the glomerular capillary wall failed to discriminate between IgG species with isoelectric points that ranged from 5.5 to 8.5 (Fig. 2). That proteinuria in these patients derived, at least in part, from diminution of glomerular fixed charge content is attested to by $(a)$ the reduced capacity of the glomerular capillary wall to take up and stain with colloidal iron (38), and (b) an invariable loss of discrete epithelial foot processes.
That this latter finding is indicative of charge depletion is suggested by its reproducibility when polyanionic glomerular glycoproteins are neutralized by in vivo perfusion with polycations $(39,40)$ or removed by in vitro neuraminidase digestion (36).

Whereas a loss of electrostatic barrier function appears to be common to both nephritic patient groups, enhanced filtration of large dextran molecules in those with major IgG leakage (group II) suggests that in these latter patients there also exists a defect in the sizeselective barrier to macromolecule filtration. In accord with the findings of Hulme and Hardwicke (41), who reported selective increases in the transglomerular passage of large neutral PVP molecules in a subset of patients with glomerulonephritis, fractional clearance of dextrans with radii $>50 \AA$ was elevated in group II relative to group I patients (Fig. 3). Selectively enhanced transport of large dextran and protein (IgG) molecules suggests that the glomerular membrane in group II nephritic patients had a less sharp cutoff than that in group I patients. To test this hypothesis we devised a mathematical model of the glomerular membrane that provides a means for interpreting changes in transglomerular dextran transport in terms of membrane-pore structure. According to this model, the pathologic glomerular membrane in proliferative glomerulonephritis is composed of a parallel array of two different pore structure components. The major component is a small-pore ultrafilter which is responsible for the retention of dextrans of small radius. The minor component (i.e., the smaller part of the total membrane area) is postulated as being a large-pore ultrafilter through which large (and small) macromolecules are able to penetrate. This analysis revealed the smallpore component to be rather similar in the two patient groups and to be composed of pores, the radius of which approximated 51-55 $\AA$. In contrast, pore radius in the large-pore membrane component is computed to be much larger in group II relative to group I patients, 87-97 vs. 72-77 $\AA$, respectively (Table IV).

In analyzing the dextran filtration data we chose to postulate the existence of two discrete pore sizes rather than isoporosity because the latter is inconsistent with both the very selective increases in fractional clearance seen for large dextrans in group II relative to group I, and the intersection of the fractional dextran clearance profiles in subgroups IIa and IIb (Fig. 4). Within the context of this model, the membrane parameter values given in Table IV provide an accurate representation of the observed filtration data for all groups. Although the values given for $r_{1}, r_{2}$, and $\Omega$ in each case minimize the sum of squares of the deviations calculated from observed fractional clearances (Appendix), in a few instances a second set of parameters provides almost as satisfactory a fit to the group 
II, IIa, or IIb data. This other parameter set invariably corresponds to much larger values of $r_{2}$ (typically $\sim 170 \AA)$ and much smaller values of $\Omega(\sim 0.02)$ than those shown.

It is likely that the present results could be described equally well by other heteroporous models. An example is the approach used by one of us (BDM) previously (35) in the analysis of dextran fractional clearance data in diabetic nephropathy, in which the capillary wall was postulated to have two continuous distributions of pores. One was centered on a value similar to those given here for $r_{1}$, while the other involved relatively few pores of sufficiently large radius that no molecular sieving took place. Qualitatively, these pore properties are not unlike those of the second-best parameter sets of the present model, mentioned above. We prefer the present two-pore model because we find the functional significance of discrete pore sizes to be more readily visualized than that of continuous distributions, and because the characteristics of both sets of pores can be computed in a somewhat more direct and self-consistent manner than in the previous study just cited.

In attempting to relate the foregoing findings to proteinuria, it should be emphasized that the dextrans used to define membrane-pore structure differ from proteins not only with respect to charge but also in configuration. Clearance techniques in the rat suggest that plasma proteins are substantially more restricted by the normal glomerular capillary wall than dextrans of equivalent size and similar charge (42). This disparity has been ascribed to asphericity and molecular compliance of dextran molecules under shear, with the result that their effective molecular dimensions during transglomerular permeation are smaller than those estimated by gel permeation chromatography (43). If the clearance of proteins and equivalent-sized dextrans through the glomerular membrane in nephritic patients is similarly disparate, it remains unclear whether enhanced albumin transport in group I patients takes place through a charge-depleted large-pore region of the membrane alone, or through both small- and largepore components of the membrane. No such doubt surrounds the portal of IgG entry into Bowman's space and hence into urine. From its molecular dimensions $(\mathrm{r}=55 \AA)$, we infer that IgG is restricted totally by the small-pore component $\left(r_{1} \leq 55 \AA\right)$ in both patient groups. Whereas the large pore component in group I patients $\left(r_{2}=72-77 \AA\right)$ appears also to largely restrict IgG, the considerably larger pores in the upper mode of group II patients $\left(r_{2}=87-97 \AA\right)$ are inferred to be highly IgG permeable.

Yet another limitation of any attempt to relate dextran transport and membrane-pore structure to fractional protein clearances derives from uncertainty re- garding the contribution of tubular reabsorption to the clearance of filtered proteins. Analysis of early proximal tubule fluid in the normal rat suggests that the mechanism for tubule protein uptake is nearly saturated (19). Increased protein filtration induced by a variety of experimental glomerular injuries has been found to completely saturate the tubule protein transport process, with the result that increments in filtered protein were qualitatively excreted $(20,21)$. More indirect evidence, based on clearance techniques, has also been presented to suggest that albumin and IgG share a common tubular reabsorptive pathway (5). Inasmuch as these findings can be extrapolated to the nephritic kidney in man, group II patients appeared to have a glomerular barrier injury of graded rather than homogeneous severity. Although the radius of pores in the upper mode was similar in patients with moderate IgG leakage (subgroup IIa) to that in patients with massive IgG leakage (subgroup IIb), the membrane area fraction occupied by large pores was twoto threefold larger in the latter subgroup (Table IV).

A lower density of large IgG-permeable pores and hence smaller filtered IgG load in subgroup IIa might explain the failure of the most cationic species of plasma IgG to appear in urine. Glomerular transport theory predicts that electrical interaction between polycations and a negatively charged membrane (albeit less negatively charged than normal) should result in facilitated and not in restricted transport $(13,44)$. This paradox may be reconciled by the observation that cations bind preferentially to proximal tubule brush border $(45,46)$. Thus, facilitated tubular reabsorption rather than restricted filtration may account for the absence of cationic IgG molecules from final urine in subgroup IIa patients. Inasmuch as enhanced fractional IgG clearance reflects increased glomerular permeability to, and hence a larger filtered load of, IgG in subgroup IIb patients, it seems reasonable to infer that tubular IgG uptake in such patients was more completely saturated, permitting even preferentially bound cationic species of IgG to escape into the urine.

The profound reduction of GFR in group II patients with major IgG leakage suggests that severe damage to the glomerular capillary wall may provide a structural basis for the development of large IgG-permeable pores. On the other hand, there is also a body of evidence suggesting that the phenomenon of large protein-permeable pores within the glomerular membrane may be of a functional nature rather than be due to disease-related disruption of glomerular structure. For example, Pessina et al. (47) have observed the appearance of proteinuria and selectively enhanced filtration of large PVP molecules $(r>40 \AA)$ during angiotensin infusion in the rat, and Tiggeler et al. (48) have described an acute reduction in filtra- 
tion of large PVP and protein molecules in nephrotic patients receiving indomethacin. They have proposed that the respectively enhanced and depressed production of prostaglandins anticipated during the foregoing maneuvers may in some way modify the size-selective properties of the glomerular capillaries (48). Similarly, infusion of the polycation hexadimethrine into a rat was found by Hunsicker et al. (40) to result in a transient but massive increase in urinary excretion of proteins, prominent among which was IgG. Electrofocusing techniques revealed the excreted IgG to have a distribution of isoelectric points similar to that of plasma IgG, suggesting that a noncharge discriminatory population of large pores had appeared within the glomerular capillary wall when glomerular polyanion was neutralized. It remains uncertain, therefore, whether the appearance of large protein-permeable pores in the glomerular membrane of nephritic patients is a consequence of structural damage or results from such biophysical influences as hemodynamic and charge-selective characteristics of the glomerular capillaries.

Regardless of the precise pathogenesis of the sizeselective defects in the glomerular capillary wall, their absence or presence provides an attractive means for reinterpreting the widely used proteinuria selectivity index, and for explaining the previously reported discrepant results of this index in patients with glomerulonephritis (1-4). At the time that the selectivity index was conceived, heavy proteinuria was ascribed to a shift in glomerular pore size distribution to one of larger size than normal. The clearance ratio of a large protein such as IgG to that of a smaller protein, such as albumin or transferrin, was used as a measure of the extent to which glomerular pore size distribution was shifted to pores of larger size (1-3). Our findings suggest that in some proteinuric patients with glomerulonephritis the size-selective properties of the glomerular filter are, in fact, little altered. Under these circumstances, as in group I nephritic patients, a selective enhancement of filtration of anionic proteins of relatively small radius (such as albumin and transferrin) appears to result from an isolated loss of glomerular fixed negative charge content. Larger proteins, such as IgG, are restricted by virtue of their size alone. On the other hand, should an array of enlarged pores develop within the membrane, as in group II nephritic patients, increased quantities of IgG will be filtered into Bowman's space. As a consequence, IgG and larger plasma proteins will constitute a substantial fraction of the excreted protein in final urine. More importantly, if such large pores provide the major means of access to Bowman's space for, and are nondiscriminating toward large plasma proteins, the fractional clearance of IgG will approach that of albumin.
This provides a basis for the phenomenon known as nonselective proteinuria.

It should be emphasized that neither size- nor charge-related glomerular barrier dysfunction is unique to glomerulonephritis. For example, glomerular pore size distribution in minimal change nephropathy has been shown to be uniformly shifted to pores of smaller size than normal $(14,49,50)$. The selective proteinuria typical of this disorder appears to be a consequence of a loss of glomerular polyanion. Conversely, as judged by nonselective proteinuria and selectively enhanced transport of very large dextran and PVP molecules, focal defects (or large pores) in the size-selective barrier appear to typify many nonminimal glomerulopathies of man, including diabetic nephropathy $(28,35,41,48)$. We propose that either charge depletion alone, or charge depletion in combination with defects in the size-selective properties of the glomerular capillary wall, represent nonspecific responses to a variety of glomerular injuries, including that induced by glomerulonephritis.

\section{APPENDIX}

The mathematical model used here is a generalization of the model of Deen et al. (13) to the case of a heterogeneous membrane with two discrete pore radii. In the case of an isoporous membrane, the flux, $J_{i}$, of an uncharged solute $i$ from plasma to Bowman's space may be expressed as

where

$$
\mathrm{J}_{\mathrm{i}}=\frac{\mathrm{J}_{\mathrm{v}} \mathrm{C}_{\mathrm{i}} \mathrm{K}_{\mathrm{C}} \phi}{1-\exp (-\alpha)\left[1-\mathrm{K}_{\mathrm{C}} \phi\right]},
$$

$$
\alpha=\frac{\mathrm{K}_{\mathrm{C}} \delta}{\mathrm{fK}_{\mathrm{D}} \mathrm{D}_{\mathrm{i}}} .
$$

Here, $J_{v}$ is the transcapillary volume flux; $C_{i}$ the concentration of solute $\mathrm{i}$ in glomerular plasma; and $\alpha$ is a dimensionless measure of the relative importance of convection to diff usion for the transport of solute $i$ through the membrane pores. The quantities $K_{C}, K_{D}$, and $\phi$ express restrictions to the transport of solute $i$ on the basis of molecular size, and are evaluated as described elsewhere $(13,51) . \delta$ is the pore length; $D_{i}$ the diffusivity of solute $i$ in bulk solution; and $f$ is the fraction of the membrane surface occupied by pores.

The volume flux, $J_{v}$, is expressed as

$$
\mathrm{J}_{\mathrm{v}}=\frac{K_{\mathrm{f}}}{\mathrm{S}}\left(\Delta \mathrm{P}-\Pi_{\mathrm{G}}\right)
$$

where $K_{f}$ is the ultrafiltration coefficient, $S$ the total glomerular surface area, $\Delta P$ the transcapillary hydraulic pressure difference, and $\Pi_{G}$ the intraglomerular oncotic pressure. $\Pi_{G}$ is calculated from the local plasma concentration, $C_{p}$, using the expression

$$
\Pi_{G}=a_{1} C_{p}+a_{2} C_{p}^{2},
$$

where $a_{1}=1.63 \mathrm{~mm} \mathrm{Hg} /(\mathrm{g} / \mathrm{dl})$, and $\mathrm{a}_{2}=0.294 \mathrm{~mm} \mathrm{Hg} /$ $(\mathrm{g} / \mathrm{dl})^{2}$.

To obtain a relation between $\alpha$ and the pore radius for an isoporous membrane $\left(r_{0}\right)$, we substitute for $J_{v}$ in Eq. A2 to obtain 


$$
\alpha=\frac{K_{C} K_{f}\left(\Delta P-\Pi_{G}\right)}{K_{D} D_{i}}\left(\frac{\delta}{f S}\right)=\frac{K_{C}\left(\Delta P-\Pi_{G}\right)}{K_{D} D_{i}}\left(\frac{r_{0}^{2}}{8 \eta}\right),
$$

where the final expression in Eq. A5 results from the assumption of Poiseuille flow through parallel channels (pores) across the glomerulus, and $\eta$ is the viscosity of the glomerular filtrate.

In the case of a two-pore membrane, consisting of type 1 and type 2 pores, the total flux of solute or volume is the sum of the fluxes (based on total membrane area) through the two types of pores:

$$
\begin{aligned}
& \mathrm{J}_{\mathrm{i}}=\mathrm{J}_{\mathrm{i} 1}+\mathrm{J}_{\mathrm{i} 2}, \\
& \mathrm{~J}_{\mathrm{v}}=\mathrm{J}_{\mathrm{v} 1}+\mathrm{J}_{\mathrm{v} 2} .
\end{aligned}
$$

Here and in subsequent discussion a subscript of 1 or 2 refers to type 1 or type 2 pores of radii $r_{1}$ and $r_{2}$, respectively. The other parameter of interest is $\Omega$, the fraction of GFR permeating type 2 pores. That is, $\Omega$ is defined such that $J_{v 1}$ $=(1-\Omega) J_{v}$ and $J_{v 2}=\Omega J_{v}$. Accordingly, we also define $K_{f 1}$ $=(1-\Omega) K_{f}$ and $K_{f 2}=\Omega K_{f}$. Thus, Eq. A3, with addition of subscripts 1 or 2 holds separately for both types of pores. The overall expression for $J_{i}$, representing the additive contributions of the two pore sizes, is then

$$
\begin{aligned}
J_{i}=J_{v} C_{1}\left(\frac{(1-\Omega) K_{C 1} \phi_{1}}{1-\exp \left(-\alpha_{1}\right)\left[1-K_{C 1} \phi_{1}\right]}\right. & \\
& \left.+\frac{\Omega K_{C 2} \phi_{2}}{1-\exp \left(-\alpha_{2}\right)\left[1-K_{C_{2} \phi_{2}}\right.}\right) .
\end{aligned}
$$

The expression for $\alpha$ in Eq. A5 is valid for $\alpha_{1}$ or $\alpha_{2}$, if $r_{0}$, $K_{C}$, and $K_{D}$ are replaced by the corresponding quantities for type 1 or type 2 pores.

If $Q$ is the plasma flow rate, conservation of volume, solute, and protein within the capillary lumen is expressed by the following differential equations:

$$
\begin{aligned}
\frac{d Q}{d y} & =-J_{v} S, \\
\frac{d\left(Q C_{i}\right)}{d y} & =-J_{i} S, \\
\frac{d\left(Q C_{p}\right)}{d y} & =0 .
\end{aligned}
$$

Simultaneous numerical solution of Eqs. A9-11 allows calculation of plasma flow rate, solute concentrations, and all fluxes as functions of position ( $y$ ) along an idealized glomerular capillary. The Bowman's space-to-plasma concentration ratio $(\theta)$ is then calculated as

$$
\theta=\frac{\int_{0}^{1} J_{i} \mathrm{dy}}{C_{i \Lambda} \int_{0}^{1} J_{v} \mathrm{dy}},
$$

where $C_{i n}$ is the afferent concentration of solute $i$. Note that the position coordinate has been normalized so that $y=0$ at the afferent end and $y=1$ at the efferent end of the capillary.

For a given neutral solute and specified values of $\Delta P, C_{P A}$ (afferent arteriolar protein concentration), $K_{f}, G F R$, and ERPF $[=Q(0)], \theta$ depends only on $r_{1}, r_{2}$, and $\Omega$. Optimal values of these membrane parameters were determined iteratively, through an implementation of Powell's method of nonlinear parameter estimation (52). The parameters, $r_{1}, r_{2}$, and $\Omega$ are denoted by the vector $\beta=\left(r_{1}, r_{2}, \Omega\right)$ and the estimated values of $\hat{\beta}=\left(\hat{r}_{1}, \hat{\mathbf{r}}_{2}, \hat{\Omega}\right)$. The calculated fractional clearance for dextran of a particular size is denoted by $\theta_{i}(\hat{\beta})$. We determine the combination $\hat{\beta}$ to minimize the sum of squares $\sigma(\hat{\beta})$ :

$$
\sigma(\hat{\beta})=\sum_{i=1}^{n}\left[\theta_{i}^{\prime}(\hat{\beta})-1\right]^{2},
$$

where $n$ is the number of dextran radii investigated, and $\theta_{i}(\hat{\beta}) \equiv \theta_{1}(\hat{\beta}) / \theta_{i}$, the ratio of calculated to measured fractional clearance of solute $i$. This transformation allows for equal weighting of all values of $\theta$, motivated by the finding that for our data, the uncertainty in $\theta$ is roughly proportional to the magnitude of $\theta$.

The confidence limits for the parameters $\hat{\beta}_{i}$ were calculated from the covariance $V$, and the least squares sum $\sigma(\hat{\beta})$, where

and

$$
\mathrm{X}=\left\{\mathrm{x}_{\mathrm{ij}}\right\}=\left.\frac{\partial \theta_{\mathrm{i}}}{\partial \beta_{\mathrm{i}}}\right|_{\beta=\hat{\beta}} \quad \begin{aligned}
& \mathrm{i}=1,2,3 \\
& \mathrm{j}=1,2, \ldots, n,
\end{aligned}
$$

$$
\mathrm{V}=\left(\mathrm{v}_{\mathrm{ij}}\right) \equiv\left(\mathbf{X}^{\prime} \mathbf{X}\right)^{-1}
$$

$X^{\prime}$ denotes the transpose of the matrix $X$. The $\sim 100(1$ $-\alpha) \%$ confidence intervals for estimates of the parameters $\left(\hat{\beta}_{\mathrm{i}}\right)$ are expressed as (53):

$$
\hat{\beta}_{\mathrm{i}} \pm \mathrm{t}(n-3, \alpha)\left[v_{\mathrm{ii}} \cdot \sigma(\hat{\beta}) /(n-3)\right]^{1 / 2},
$$

where $t(n-3, \alpha)$ is the $\alpha$ percentage point of a two-tailed $t$ distribution with $n-3$ degrees of freedom. That is, $\alpha$ is the probability that $|t| \geq t(n-3, \alpha)$.

\section{ACKNOWLEDGMENTS}

This study was supported in part by National Institutes of Health grants 1 R01 AM29985-01, 5R01 AM 20368-05, and in part by a grant from the Kroc Foundation. Dr. Friedman is a fellow of the National Institutes of Health grant 5T32 AM07357-02. Dr. Bridges is a fellow of the Whitaker Health Sciences Fund.

\section{REFERENCES}

1. Blainey, J. D., D. B. Brewer, J. H. Hardwicke, and J. F Soothill. 1960. The nephrotic syndrome. Diagnosis by renal biopsy and biochemical and immunological analyses related to the response to steroid therapy. Q. J. Med. 235: 29-39.

2. Joachim, G. R., J. S. Cameron, M. Schwartz, and E. L. Becker. 1964. Selectivity of protein excretion in patients with the nephrotic syndrome. J. Clin. Invest. 43: 23322346.

3. Cameron, J. S., and G. Blandford. 1966. The simple assessment of selectivity in heavy proteinuria. Lancet II: 242-247.

4. Hardwicke, J., J. S. Cameron, J. F. Harrison, B. Hulme, and J. F. Soothill. 1970. Proteinuria studied by clearances of individual macromolecules. In Proteins in Normal and Pathological Urine. Y. Manuel, J. P. Revillard, and H. Betuel, editors. University Park Press, Baltimore. 128.

5. Hardwicke, J., and J. R. Squire. 1955. The relationship between plasma albumin concentration and protein excretion in patients with proteinuria. Clin. Sci. (Lond.). 14: $509-530$. 
6. Gregoire, F., C. Malmendier, and P. P. Lambert. 1958. The mechanism of proteinuria and a study of the effects of hormonal therapy in the nephrotic syndrome. Am. J. Med. 25: 516-531.

7. Chinard, F. P., H. D. Lanson, H. A. Eder, R. L. Greig, and A. Miller. 1954. A study of the mechanism of proteinuria in patients with the nephrotic syndrome. J. Clin. Invest. 33: 621-628.

8. Rennke, H. G., and M. A. Venkatachalam. 1977. Glomerular permeability: in vivo tracer studies with polyanionic and polycationic ferritins. Kidney Int. 11: 44-53.

9. Brenner, B. M., T. H. Hostetter, and H. D. Humes. 1978. Glomerular permselectivity: barrier function based on discrimination of molecular size and charge. Am. J. Physiol. 234: F455-F460.

10. Deen, W. M., and B. Satvat. 1981. Determinants of the glomerular filtration of proteins. Am. J. Physiol. 10: F162-F170.

11. Chang, R. L. S., I. F. Ueki, J. L. Troy, W. M. Deen, C. R. Robertson, and B. M. Brenner. 1975. Permselectivity of the glomerular capillary wall to macromolecules: II. Experimental studies in rats using neutral dextran. Biophys. J. 15: 887-895.

12. Chang, R. L. S., C. R. Robertson, W. M. Deen, and B. M. Brenner. 1975. Permselectivity of the glomerular capillary wall to macromolecules: I. Theoretical considerations. Biophys. J. 15: 861-886.

13. Deen, W. M., B. Satvat, and J. M. Jamieson. 1980. Theoretical model for glomerular filtration of charged solutes. Am. J. Physiol. 238: F126-F139.

14. Winetz, J. A., C. R. Robertson, H. V. Golbetz, B. J. Carrie, W. R. Salyer, and B. D. Myers. 1981. The nature of the glomerular injury in minimal change and focal sclerosing glomerulopathies. Am. J. Kidney Dis. 1: 91-97.

15. Chang, R. L. S., W. M. Deen, C. R. Robertson, C. M. Bennett, R. J. Glassock, and B. M. Brenner. 1976. Permselectivity of the glomerular capillary wall. Studies of experimental glomerulonephritis in the rat using neutral dextran. J. Clin. Invest. 57: 1272-1280.

16. Howard, A., and G. Virella. 1969. The separation of pooled human IgG into fractions by isoelectric focusing. Protides Biol. Fluids Proc. Colloq. 17: 449-453.

17. Peterson, P. A., and I. Berggard. 1971. Urinary immunoglobulin components in normal, tubular, and glomerular proteinuria: quantities and characteristics of free light chains, IgG, IgA and $F_{C Y}$ fragment. Eur. J. Clin. Invest. 1: 255-264.

18. Hardwicke, J., R. White, and A. Williams. 1976. Molecular size of IgG in patients with focal glomerulosclerosis. Clin. Nephrol. 6: 290-294.

19. Oken, D. E., B. B. Kirschbaum, and D. M. Landwehr. 1981. Micropuncture studies of the mechanisms of normal and pathologic albuminuria. Contrib. Nephrol. 24: 1-7.

20. Landwehr, D. M., J. S. Carvalho, and D. E. Oken. 1977. Micropuncture studies of the filtration and absorption of albumin by nephrotic rats. Kidney Int. 11: 9-17.

21. Eisenbach, G. M., J. B. Van Liew, and J. W. Boylan. 1975. Effect of angiotensin on the filtration of protein in the rat kidney. A micropuncture study. Kidney Int. 8: 80-87.

22. Myers, B. D., F. Chui, M. Hilberman, and A. S. Michaels. 1979. Transtubular leakage of glomerular filtrate in human acute renal failure. Am. J. Physiol. 237: F319F325.

23. Fjeldbo, W., and T. A. Stamey. 1968. Adapted method for determination of inulin in serum and urine with an autoanalyzer. J. Lab. Clin. Med. 72: 353-358.

24. Harvey, R. B., and A. J. Brothers. 1962. Renal extraction of para-aminohippurate and creatinine measured by continuous in vivo sampling of arterial and renal vein blood. Ann. N. Y. Acad. Sci. 102: 46-54.

25. Laurent, T. C., and J. Killander. 1964. A theory of gel filtration and its experimental verification. J. Chromatogr. 14: 317-330.

26. Granath, K. A., and B. E. Kvist. 1967. Molecular weight distribution analysis of gel chromatography on Sephadex. J. Chromatogr. 28: 69-81.

27. Scott, T. A., and E. H. Melvin. 1953. Determination of dextran with anthrone. Anal. Chem. 25: 1656-1661.

28. Carrie, B. J., and B. D. Myers. 1980. Proteinuria and functional characteristics of the glomerular barrier in diabetic nephropathy. Kidney Int. 17: 669-676.

29. Weeke, B. 1973. Rocket immunoelectrophoresis. Scand. J. Immunol. 2(Suppl. 1): 37-46.

30. Sodderholm, J., C. J. Smyth, and T. Wadstrom. 1975. A simple and reproducible method for crossed-immunoelectrofocusing. Comparative studies on microheterogeneity of diphtheria toxin from different preparations. Scand. J. Immunol. 4(Suppl. 2): 107-113.

31. Kronvall, G., and R. C. Williams, Jr. 1969. Differences in antiprotein A activity among IgG subgroups. J. Immunol. 103: 828-833.

32. Harboe, M., and I. Folling. 1974. Recognition of two distinct groups of human IgM and IgA based on different binding to staphylococci. Scand. J. Immunol. 3: 471482.

33. Michael, A. F., E. Blau, and R. L. Vernier. 1970. Glomerular polyanion: alteration in aminonucleoside nephrosis. Lab. Invest. 23: 649-657.

34. Deen, W. M., C. R. Robertson, and B. M. Brenner. 1972. A model of glomerular ultrafiltration in the rat. Am. J. Physiol. 223: 1178-1183.

35. Myers, B. D., J. A. Winetz, F. Chui, and A. S. Michaels. 1982. Mechanisms of proteinuria in diabetic nephropathy: a study of glomerular barrier function. Kidney Int. 21: $96-105$.

36. Andrews, P. M. 1979. Glomerular epithelial alterations resulting from sialic acid surface coat removal. Kidney Int. 15: 376-385.

37. Bennett, C. M., R. J. Glassock, R. L. S. Chang, W. M Deen, C. R. Robertson, and B. M. Brenner. 1976. Permselectivity of the glomerular capillary wall. Studies of experimental glomerulonephritis in the rat using dextran sulfate. J. Clin. Invest. 57: 1287-1294.

38. Blau, E. B., and D. E. Hass. 1973. Glomerular sialic acid and proteinuria in human renal disease. Lab. Invest. 28: 477-481.

39. Seiler, W. M., M. A. Venkatachalam, and R. S. Cotran. 1975. Glomerular epithelium: structural alterations induced by polycations. Science (Wash., DC). 189: 390393.

40. Hunsicker, L. G., T. P. Shearer, and S. J. Shaffer. 1981. Acute reversible proteinuria induced by infusion of the polycation hexadimethrine. Kidney Int. 20: 7-17.

41. Hulme, B., and J. Hardwicke. 1968. Human glomerular permeability to macromolecules in health and disease. Clin. Sci. (Lond.). 34: 515-529.

42. Rennke, H. G., Y. Patel, and M. A. Venkatachalam. 1978. Glomerular filtration of proteins: clearances of anionic, neutral, and cationic horseradish peroxidase in the rat. Kidney Int. 13: 324-328.

43. Venkatachalam, M. A., and H. G. Rennke. 1978. The 
structural and molecular basis of glomerular filtration Circ. Res. 43: 337-347.

44. Bohrer, M. P., C. Bayliss, H. D. Humes, R. J. Glassock, C. R. Robertson, and B. M. Brenner. 1978. Permselectivity of the glomerular capillary wall. Facilitated filtration of circulating polycations. J. Clin. Invest. 61: 72-78.

45. Just, M., and E. Habermann. 1973. Interactions of a protease inhibitor and other peptides with isolated brush border membranes from rat renal cortex. NaunynSchmiedeberg's Arch. Pharmacol. 280: 161-176.

46. Mogensen, C. A., K. Sølling, and E. Vittinghus. 1981. Studies on mechanisms of proteinuria using amino acidinduced inhibition of tubular reabsorption in normal and diabetic man. Contrib. Nephrol. 26: 50-65.

47. Pessina, A. C., B. Hulme, and W. S. Peart. 1972. Renininduced proteinuria and the effects of adrenalectomy. II. Morphology in relation to function. Proc. R. Soc. Lond. B Biol. Sci. 180: 61-71.
48. Tiggeler, R. G. W. L., B. Hulme, and P. G. A. B. Mijdeveld. 1979. Effect of indomethacin on glomerular permeability in the nephrotic syndrome. Kidney Int. 16: 312-321.

49. Robson, A. M., J. Giangiacomo, R. A. Kienstra, S. T. Naqvi, and J. R. Ingelfinger. 1974. Normal glomerular permeability and its modification by minimal change nephrotic syndrome. J. Clin. Invest. 54: 1190-1199.

50. Carrie, B. J., W. R. Salyer, and B. D. Myers. 1981. Minimal change nephropathy: an electrochemical disorder of the glomerular membrane. Am. J. Med. 70: 262-268.

51. Deen, W. M., M. P. Bohrer, and B. M. Brenner. 1979. Macromolecule transport across glomerular capillaries: application of pore theory. Kidney Int 16: 353-365.

52. Powell, M. J. D. 1965. A method for minimizing a sum of squares of non-linear functions without calculating derivatives. Computer J. 7: 303-307.

53. Draper, N. R., and H. Smith. 1966. Applied Regression Analysis. John Wiley \& Sons, New York. 65: 273. 